\title{
GUIDANCE TOOL FOR WASTE ANALYSIS IN AN ACCREDITED LABORATORY
}

\author{
$\underline{\text { Diana Puiu }}^{1}$, Liliana Valeria Cruceru ${ }^{1}$ \\ 1INCD ECOIND, 71-73, Str. Podu Dâmboviței, Bucharest, Romania, email: \\ diana puiu@gmail.com
}

\begin{abstract}
The characterisation and classification of waste for transportation, recycle, storage or removal is provided by the EU legislation framework in order to control accidents hazards with consequence for human health and the environment.

This paper proposes a guidance for an accredited laboratory as a methodological tool in waste analysis to be used at local and regional level due to the current Romanian environmental legislation. Analytical tests are required to establish the exceeding maximum allowable concentration of physico-chemical characteristics of different types of wastes. The assessment of characteristics waste status can be made by analyzing all the waste composition, or the separated fractions of liquid or solid phases, or the leacheable content. To answer to the need of enhancing the precision and comparability of waste analysis data, there are suitable standardized methods available for sampling, treatment and analysis.

A review of actual legislation and standardized methods for waste analysis is presented briefly in this paper.
\end{abstract}

Keywords: legislation, physico-chemical characteristics, standards, waste

\section{Introduction}

A waste is any solid, liquid or contained gaseous material that is discharged by being disposed of, burned, incinerated or recycled. It can be the byproduct of a manufacturing process or simply a commercial product that is being disposed of. Even materials that are recycled or can be reused in some way might be considered waste. The presence of waste is an indication of over consumption and that materials are not being used efficiently. At international level important waste management measures are undertaken in order to reduce the high quantities of wastes by reducing the production of waste through education and the adaptation of improved production processes, by recycling or by waste processing through thermal, chemical or biological means. In order to classify the waste, to establish the proper transportation conditions and to indicate the specific criteria for acceptance in different classes of landfills a complete analytical investigation is necessary to be done. For this, proper methodologies for taking and preparation of samples function of the type of waste, and specific standardized analytical methods for each parameter must be implemented at the level of the laboratory. A guide to include the most important standards and norms related to the analytical characterization of waste represents a useful tool for every accredited laboratory involved in the process of analytical control of this type of samples. 


\section{Wide common types of waste. A classification}

According to Waste Framework Directive, 2008/98/EC [1], wastes are defined as endof-use products which holders intend or need to discard. In order to protect the environment and the human health by the risk of accidents, because of proprieties and composition of wastes, Seveso III Directive, 2012/18/EU [2] was adopted to consider the toxicity of dangerous substances, and Waste Directive defines the hazard proprieties of waste. Implementation of Waste Directive in Romania was done by the Law 211/2011 [3], on waste regime, which excludes radioactive wastes, gaseous effluents emitted into the atmosphere, decommissioned explosives and bio-wastes. These need a special treatment and are not the objective of the present study.

Table 1 Wastes classification by its organic or inorganic content

\begin{tabular}{|c|c|c|c|}
\hline \multirow{8}{*}{ Solid waste } & \multirow{5}{*}{$\begin{array}{l}\text { Inorganic } \\
\text { materials }\end{array}$} & \multirow{3}{*}{ Metals } & Ash \\
\hline & & & Slag \\
\hline & & & Asbestos \\
\hline & & \multirow[b]{2}{*}{ Non-metals } & Glass \\
\hline & & & $\begin{array}{l}\text { Construction } \\
\text { materials }\end{array}$ \\
\hline & \multirow{3}{*}{$\begin{array}{l}\text { Organic } \\
\text { materials }\end{array}$} & \multicolumn{2}{|l|}{ Plastics } \\
\hline & & \multicolumn{2}{|c|}{ Textile materials } \\
\hline & & \multicolumn{2}{|l|}{ Coal } \\
\hline \multirow{7}{*}{ Liquid waste } & \multirow{2}{*}{ Inorganic } & \multicolumn{2}{|l|}{ Acids } \\
\hline & & \multicolumn{2}{|l|}{ Alkalis } \\
\hline & \multirow{5}{*}{ Organic } & \multicolumn{2}{|l|}{ Solvents } \\
\hline & & \multicolumn{2}{|c|}{ Cleaning products } \\
\hline & & $\begin{array}{l}\text { Petroleum } \\
\text { products }\end{array}$ & Oil \\
\hline & & \multicolumn{2}{|l|}{ Emulsions } \\
\hline & & \multicolumn{2}{|c|}{ Paint and varnishes } \\
\hline
\end{tabular}

A list of waste classification is available due to HG 856/2002 [4] about waste management, and is actualized by European LoW [5] where wastes are classified in 20 major groups by different criteria like industry sector waste producer or by waste generating processes, or by type, main component or polluting component, or by hazard and physical propriety. According to groups and subgroups, the different types of wastes in the list are fully defined by the six-digit code for the waste and the respective two-digit and four-digit chapter headings.

Table 2 Physical state of the wastes

\begin{tabular}{|c|c|c|c|}
\hline 1 & Liquid & 9 & Fine particles, powder and dust \\
\hline 2 & Solution & 10 & Scales, flakes \\
\hline 3 & Suspension & 11 & Fibers and wool \\
\hline 4 & Emulsion & 12 & Fragments \\
\hline 5 & Sludge & 13 & Massive or glazed \\
\hline 6 & Liquid sludge & 14 & Slag \\
\hline 7 & Slurry & 15 & Deep frozen \\
\hline 8 & Solid & 16 & Sharp and other \\
\hline
\end{tabular}


Classifying the waste due to matrix composition can give an overview of waste testing program dedicated to the determination of one or several parameters by suitable methods.

In order to characterize correctly the waste with a certain code must be considered the main component (table1), the physical form (table 2), the waste producer process and the hazard of the waste. Usually wastes are a mixture of different residues presented in various physical forms, in one or more fractions.

\section{Romanian legislation for waste management}

The Law no. 211/2011 [3] describes the measures strategy in order to prevent the waste impact on human health and the environment. The most important characteristic is the defining of hazardous status of waste. In Annex no. 4 wastes are described in terms of explosive, oxidants, flammable, harmful, toxic, corrosive, carcinogen, infectious, irritant, ecotoxic etc. If only one of these characteristics is applied to the waste sample, then the sample is classified as hazardous.

Assessing waste against limit values can be done due to section 8, of HG 856/2002 [4]. It is stated that the waste is a mixture of substances, so the chemical proprieties can be evaluated by composition or by leachability. In order to identify the relevant substances for analytical tests, it is necessary a basic characterization of wastes which can be done by obtaining background information about the particular waste. The role of each substance can be related to the specific risk phrases which can be consulted in Regulation (EC) no. 1272/2008 [6]. In the List of Waste, hazardous wastes are identified by a code marked with an asterisk. The usual parameters that are determined for assessment of waste hazardousness includes heavy metals, major metals, anions, total organic carbon, water content, ash content, $\mathrm{pH}$, volatile and semi-volatile content or elemental content [7], but, depending on the type of waste sample, specific parameters which are suspected to be present in the sample composition, must be analyzed.

To know the hazardousness or non-hazardousness of waste [8] is important and, also, necessary for waste transportation. HG 1061/2008 [9] enforces the strategy for the transportation of non-hazardous and hazardous waste which includes a list of required indicators (table 3) for approval of hazardous waste transport on Romanian territory. It also requires the name and the waste classification code according to HG 856/2002 [4].

Table 3 List of indicators for approval of hazardous waste transport

\begin{tabular}{|c|c|c|c|}
\hline \multicolumn{5}{|c|}{ HG 1061/2008 } \\
\hline 1 & $\begin{array}{c}\text { As, } \mathrm{Pb}, \mathrm{Cd}, \mathrm{Cr} \mathrm{VI}, \mathrm{Cu}, \mathrm{Ni}, \\
\mathrm{Hg}, \mathrm{Se}, \mathrm{Te}, \mathrm{Tl}, \mathrm{Sn}, \mathrm{Sb}\end{array}$ & 7 & $\begin{array}{c}\text { Extractable component of } \\
\text { the basic substances }\end{array}$ \\
\hline 2 & $\mathrm{Cl}^{-}, \mathrm{I}^{-}, \mathrm{F}^{-}, \mathrm{Br}^{-}$ & 8 & Calorific value \\
\hline 3 & $\mathrm{SO}_{4}{ }^{-2}, \mathrm{NO}_{3}^{-}$ & 9 & Flash point \\
\hline 4 & $\mathrm{PCB}^{-} \mathrm{PCT}^{-}$ & 10 & Loss on ignition \\
\hline 5 & Lipophilic extracts & 11 & COD \\
\hline 6 & Water content & 12 & $\mathrm{pH}$, electrical conductivity \\
\hline
\end{tabular}


The least preferable option in eliminating the waste is landfilling. Order no. 95/2005 [10] classifies the landfills by waste impact on the environment in: landfills for inert waste, landfills for non-hazardous waste and landfills for hazardous waste; it also establishes the acceptance criteria and preliminary procedures for the acceptance of waste storage and the national list of waste accepted in each class of landfill. Moreover, it has specific criteria for accepting hazardous waste in landfills for nonhazardous waste. Some types of wastes may not be accepted in any landfill because of their liquid state, flammable or explosive characteristic, due to oxidative or infectious condition or any criteria which does not meet the acceptance. Moreover, the order is specific for storage of wastes with granular distribution.

These types of wastes are analyzed by their leaching or percolation behavior and by their content of total organic carbon, loss of ignition, acid neutralization capacity, etc. as is indicated in Table 4.

The Order 95/2005 [10] suggests also the analytical standard methods that can be used in analyzing the samples. Either, the order does not specify whether the waste storage must be coded or classified as dangerous.

Table 4 Requested indicators for storage in landfills according to Order no. 95/2005

\begin{tabular}{|c|c|c|c|}
\hline Parameter & $\begin{array}{l}\text { Landfill for } \\
\text { inert waste }\end{array}$ & $\begin{array}{l}\text { Landfill for } \\
\text { non- } \\
\text { hazardous } \\
\text { waste }\end{array}$ & $\begin{array}{l}\text { Landfill } \\
\text { for } \\
\text { hazardous } \\
\text { waste }\end{array}$ \\
\hline \multicolumn{4}{|c|}{ Leaching $\mathrm{L} / \mathrm{S}=2 \mathrm{l} / \mathrm{kg}$ or $\mathrm{L} / \mathrm{S}=10 \mathrm{l} / \mathrm{kg}$ or percolation test $\mathrm{C}_{0}$} \\
\hline $\begin{array}{c}\text { As, } \mathrm{Ba}, \mathrm{Cd}, \mathrm{Cr} \\
\text { total, } \mathrm{Cu}, \mathrm{Hg}, \\
\mathrm{Mo}, \mathrm{Ni}, \mathrm{Pb}, \mathrm{Sb} \\
\mathrm{Se}, \mathrm{Zn}\end{array}$ & $X$ & $\mathrm{X}$ & $X$ \\
\hline Chloride & $X$ & $X$ & $X$ \\
\hline Fluoride & $X$ & $X$ & $X$ \\
\hline Sulphates & $\mathrm{X}$ & $\mathrm{X}$ & $\mathrm{X}$ \\
\hline Phenol index & $X$ & - & - \\
\hline DOC & $\mathrm{X}$ & $\mathrm{X}$ & $\mathrm{X}$ \\
\hline TDS & $\mathrm{X}$ & $\mathrm{X}$ & $\mathrm{X}$ \\
\hline \multicolumn{4}{|c|}{ Dry matter } \\
\hline TOC & $\mathrm{X}$ & $X^{*}$ & $X$ \\
\hline BTEX & $\mathrm{X}$ & - & - \\
\hline PCBs & $X$ & - & - \\
\hline $\begin{array}{c}\text { Mineral oil } \\
\text { (C10 to C40) }\end{array}$ & $X$ & - & - \\
\hline $\mathrm{PAHs}$ & $\mathrm{X}$ & - & - \\
\hline $\mathrm{pH}$ & - & $X^{*}$ & - \\
\hline ANC & - & $\mathrm{X}^{*}$ & $X$ \\
\hline LOI & - & - & $\mathrm{X}$ \\
\hline
\end{tabular}

* These criteria are applied in addition for hazardous waste storage in landfilling for nonhazardous waste. 


\section{Testing program for waste characterization}

Before the waste will be treated, stored, or disposed, it is required a detailed chemical and physical analysis of a representative waste sample. The specific and relevant indicators which have to be analyzed are established for the basic characterization and they depend on the nature of the waste. Verification shows if the waste is within the limit value sets for critical indicators. It is recommended that the analyses will be carried out in a laboratory under ISO 17025:2005 accreditation requirements.

To ensure reliable and comparable results it is useful to follow a suitable testing program which describes the relevant steps and actions. According to SR EN 16457:2014 [11], an overview about the steps of a testing program is summarized in Figure 1. For this purpose other guidelines are available for sampling and analysis of ashes [12], or more extended with a focus on quality management and analytical data recording for industrial or municipal wastewater [13].

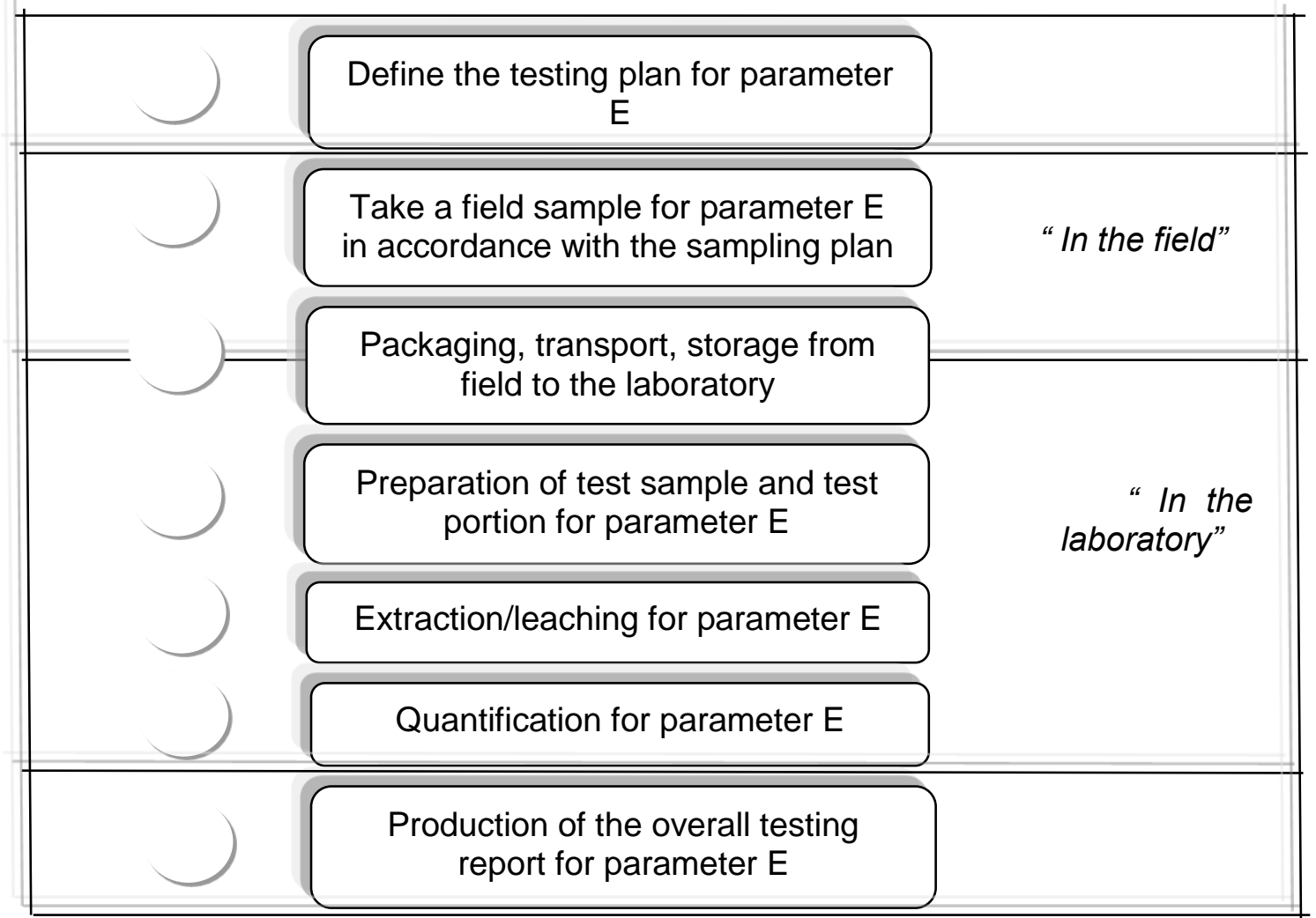

Figure 1 The seven testing steps of a waste testing programme for a given parameter $\mathrm{E}$

\section{1) Testing plan}

The complexity of the nature of the waste samples and the amount of the parameters which have to be analyzed requires a testing plan that will take into account sampling, packaging, transport, storage, preparation, extraction particularities for each parameter. For example, when volatile and non-volatile substances need to be quantified, sampling and packaging requires different handling of the samples. Also, an overview of the test will give the quantity and number of samples. In Annex A of SR EN 16457:2014 [10] is given a guidance on the choice of testing plan for each parameter with a suitable proposed standard for every step mentioned above. 


\section{2) Sampling}

The major error source comes from inappropriate sampling of wastes; the reason is that the sample is unrepresentative for its purpose and cannot be reproducible. When sampling for volatile contaminants, precautions must be taken to prevent evaporative losses. Validated guidance on waste sampling plan is given by EN 14899/2006 [14]. Due to the wide variety of waste types, situations and objectives of sampling, this Framework Standard is based on several technical reports which provide guidance on selection and application of criteria for sampling under various conditions [15], on sampling techniques for liquid, granular, sludge or slurry wastes [16], on procedures for sub-sampling in the field due to overall size of the sample to be transported [17], on procedures for sample packaging, storage, preservation, transport and delivery, for all types of waste [18], on the process of defining the Sampling Plan [19].

\section{3) Transporting and preservation}

After sampling, the samples must be chemically/physically preserved to avoid the possible chemical changes that can occur until it is analyzed. For example soil is recommended to be stored below $6^{\circ} \mathrm{C}$ because of possible risk of changing the concentration of contaminants under microbial action accelerated by moisture. For liquid wastes, pre-treatments like freezing, cooling, acidification, solvent extraction, filtration and others can be applied according to SR EN ISO 5667-3/2008 [20]. In transporting the wastes it must be taken into account the maximum time of preservation the samples in conditions of decontamination, in suitable types of containers, for analysis of various parameters. But actually, the selected analytical method gives the most suitable preservation technique. Guidance on preservation techniques for liquid, solid, sludge or slurry waste could be sought on SR CEN/TR 15310-4/2009 [18].

\section{4) Preparation of test sample}

Pre-treatment and treatment of the samples will be taken considering the nature of the sample, usually liquid or solid and function of the volatility of each parameter. But when multiple immiscible phases or fractions are present, the analysis will be performed on each separated phase or fraction, and then the results will be quantified. The test sample should be prepared for analysis according to the requirements of standard SR EN 15002/2015 [21].

\section{5) Extraction/leaching}

Depending on the interest of analysis, different analytical tests can be applied on samples in order to determine the all quantity of the analyte, or the quantity in the leachable fraction. In case of total extraction of elements from soil or total extraction of organic compounds particular techniques are well described on Hennebert's analytical protocol [7]. On the other way, in accordance with landfilling Order 95 [10], different leaching test procedures may be needed in order to characterize the wastes for assessing the risks of leaching of contaminants to the environment. Current practice for leaching waste is predominantly focused on size particle, below $4 \mathrm{~mm}$ [22-24] or 10 $\mathrm{mm}[25]$ and on different liquid:solid ratio, L/S=2 [21,23], L/S $=10$ [22,24], and is based on main methodology of leaching behavior SR EN 12920+A1/2010 [26]. The tests results allow making a distinction between different types of release of analytes in eluent under the influence of interaction of eluent with waste matrix. 


\section{6) Quantifying}

The relevance of the results for the entire sample is observed in mass balance value. Mass balance of the liquid waste is characterized by the sum of concentrations of major constituents like water content, ash content, volatiles and semi-volatiles who should reach $90 \% \mathrm{w} / \mathrm{w}$. For solid wastes the sum of content parameters concentrations is reported on dry matter and is better to be within between $90 \%$ and $110 \%$.

Analytical performance of the methods is given by the measurement of statistical parameters like accuracy, precision (repeatability and intermediate precision), specificity, detection limit, quantification limit, linearity range and robustness, based on SR ISO 5725 standards series [27]; also the uncertainty of measurement is calculated by GUM [28].

Methods of analysis and quantification of interest compounds are summarized by SR EN 16192/2012 [29] for eluates, or presented in analytical protocols [7] for solid and liquid waste.

\section{7) Testing report}

The reporting test shall provide all information that characterize the wastes in accordance with SR EN 16457 [10] and with national accreditation body requirements according to SR EN ISO 17025:2005.

\section{Conclusions}

Considering the legal and regulatory framework of wastes, specific analysis must be done for characterizing the waste as hazardous or non-hazardous and for codifying it as it is required by law 211/2011, or for approval of waste transport on Romania's territory, HG 1061/2008, or in order to store in a suitable landfill, Order 95/2005.

For analytical performance and comparable results, it is useful for accredited laboratories to develop and complete a testing program under SR EN 16457:2014 [10] requirements.

This work aims to be a useful methodological tool which suggests the suited steps to be followed by accredited or non-accredited laboratories, for waste analyzes, in accordance with afferent legal requirements.

\section{References}

[1] Directive 2008/98/EC of the European Parliament and of the Council of 19 November 2008 on waste and repealing certain Directives

[2] Seveso III Directive 2012/18/EU, Directive of the European Parliament and of the Council of 4 July 2012 on the control of major-accident hazards involving dangerous substances, amending and subsequently repealing Council Directive 96/82/EC

[3] Law no. 211 from 15 Nov 2011 about waste regime

[4] HG 856/2002, Hotarare nr. 856 din 16 august 2002 privind evidenta gestiunii deseurilor si pentru aprobarea listei cuprinzand deseurile, inclusiv deseurile periculoase

[5] Review of the European List of Waste (2008) Ökopol GmbH

[6] CLP: Regulation (EC) no. 1272/2008 of the European Parliament and of the Council of 16 December 2008 on classification, labelling and packaging of substances and mixtures, amending and repealing Directives 67/548/EEC and 1999/45/EC, and amending Regulation (EC) No 1907/2006

[7] Pierre Hennebert, Arnaud Papin, Jean-Marie Padox, Benoît Hasebrouck (2013) The evaluation of an analytical protocol for the determination of substances in waste for hazard classification, Waste Management, Elsevier, 33 (7), pp.1577-88 
[8] Doina Guta, Gheorghe Batrinescu, Adriana Cuciureanu (2013) Determining the dangerousness of waste, International symposium - SIMI 2013 "The environment and the industry" http://www.simiecoind.ro/wp-content/uploads/2015/04/DETERMINING-THEDANGEROUSNESS.pdf

[9] HG 1061/2008, HOTĂRÂRE Nr. 1061 din 10 septembrie 2008 privind transportul deşeurilor periculoase şi nepericuloase pe teritoriul României

[10] Ordin nr. 95 din 12 februarie 2005 privind stabilirea criteriilor de acceptare şi procedurilor preliminare de acceptare a deşeurilor la depozitare şi lista naţională de deşeuri acceptate în fiecare clasă de depozit de deşeuri

[11] SR EN 16457:2014 - Characterization of waste - Framework for the preparation and application of a testing programme - Objectives, planning and report

[12] M4: Guidelines for Ash Sampling and Analysis (2016) Technical Guidance Note (Monitoring), Environment Agency

[13] Protocol for the sampling and analysis of Industrial/municipal wastewater (1999) The MISA (Municipal and Industrial Strategy for Abatement)

[14] SR EN 14899:2006 Characterization of waste - Sampling of waste materials - Framework for the preparation and application of a sampling plan

[15] SR CEN/TR 15310-1/2009 Characterization of waste - Sampling of waste materials - Part 1: Guidance on selection and application of criteria for sampling under various conditions

[16] SR CEN/TR 15310-2/2009 Characterization of waste - Sampling of waste materials - Part 2: Guidance on sampling techniques

[17] SR CEN/TR 15310-3/2009 Characterization of waste - Sampling of waste materials - Part 3: Guidance on procedures for sub-sampling in the field

[18] SR CEN/TR 15310-4/2009 Characterization of waste - Sampling of waste materials - Part 4: Guidance on procedures for sample packaging, storage, preservation, transport and delivery [19] SR CEN/TR 15310-5/2009 Characterization of waste - Sampling of waste materials - Part 5: Guidance on the process of defining the sampling plan

[20] SR EN ISO 5667-3/2013 Water quality - Sampling - Part 3: Preservation and handling of water samples (ISO 5667-3:2012)

[21] SR EN 15002:2015 Characterization of waste - Preparation of test portions from the laboratory sample

[22] SR EN 12457-1/2003 Characterisation of waste. Leaching. Compliance test for leaching of granular waste materials and sludges. One stage batch test at a liquid to solid ratio of $2 \mathrm{l} / \mathrm{kg}$ for materials with high solid content and with particle size below $4 \mathrm{~mm}$ (without or with size reduction)

[23] SR EN 12457-2/2003 Characterisation of waste. Leaching. Compliance test for leaching of granular waste materials and sludges. One stage batch test at a liquid to solid ratio of 10 $\mathrm{l} / \mathrm{kg}$ for materials with particle size below $4 \mathrm{~mm}$ (without or with size reduction)

[24] SR EN 12457-3/2003 Characterisation of waste. Leaching. Compliance test for leaching of granular waste materials and sludges. Two stage batch test at a liquid to solid ratio of $2 \mathrm{l} / \mathrm{kg}$ and $8 \mathrm{l} / \mathrm{kg}$ for materials with a high solid content and with a particle size below $4 \mathrm{~mm}$ (without or with size reduction)

[25] SR EN 12457-4/2003 Characterisation of waste. Leaching. Compliance test for leaching of granular waste materials and sludges. One stage batch test at a liquid to solid ratio of 10 $\mathrm{l} / \mathrm{kg}$ for materials with particle size below $10 \mathrm{~mm}$ (without or with size reduction)

[26] SR EN 12920+A1/2010 Characterization of waste. Methodology for the determination of the leaching behaviour of waste under specified conditions

[27] SR ISO 5725-2:2002 Accuracy (trueness and precision) of measurement methods and results. Part 2: Basic method for the determination of repetability and reproductibility of a standard measurement method

[28] JCGM 100 (2008) GUM: Evaluation of measurement data - Guide to the expression of uncertainty in measurement

[29] SR EN 16192/2012 Characterization of waste - Analysis of eluates 